Research Article

DOI: http://dx.doi.org/10.18203/issn.2454-5929.ijohns20161595

\title{
Evaluation of the medical and surgical management of chronic rhinosinusitis with polyposis
}

\author{
Neetu Modgil* \\ Department of ENT, Mallareddy Institute of Medical Sciences, Suraram, Hyderabad, Telangana, India
}

Received: 15 May 2016

Accepted: 24 May 2016

*Correspondence:

Dr. Neetu Modgil,

E-mail: modgilneetu@gmail.com

Copyright: ( $)$ the author(s), publisher and licensee Medip Academy. This is an open-access article distributed under the terms of the Creative Commons Attribution Non-Commercial License, which permits unrestricted non-commercial use, distribution, and reproduction in any medium, provided the original work is properly cited.

\begin{abstract}
Background: Chronic rhinosinusitis (CRS) is a group of disorders characterized by inflammation of the mucosa of the nose and paranasal sinuses of at least 12 consecutive weeks duration. Surgical intervention may be required if severe symptoms of obstruction and infection prove medical treatment to be ineffective. Little is known about the outcomes of patients electing to continue medical management or the comparative effectiveness of continued medical therapy with FESS.

Methods: The study was conducted on 126 adult patients in the age group of 18-55 who fulfilled the CRS criteria with nasal polyposis. All patients were medically treated for the CRS, and observed after 3 weeks. In case the treatment was not effective; they were scheduled for FESS intervention and further observed after another 6 weeks. The improvement of the patients was measured by Visual analogue score, nasal endoscopy score and saccharine test.

Results: Males between 41-50 were the most common patients with CRS. There was a significant improvement in the VAS score, nasal endoscopy score after 3 weeks of medical treatment. In $88 \%$ of patients the saccharine score was normal showing that this was not an effective measure for assessing the improvement.

Conclusions: Medical treatment was found to be sufficient to treat most symptoms of CRS with nasal polyposis (grade 1 and 2). Surgery should only be done in refractory cases. Selection of those patients who will benefit from surgery should be based on the patient's symptoms and not on the examiner's polyp score. Quality of life is not proportional to polyp size (Upto grade 2).
\end{abstract}

Keywords: Chronic rhinosinusitis, Visual analogue scale, Nasal endoscopy, Saccharine test

\section{INTRODUCTION}

Chronic Rhinosinusitis (CRS) is a group of disorders characterized by inflammation of the mucosa of the nose and paranasal sinuses of atleast 12 consecutive weeks duration, thus becoming one of the most common disorders of the upper airways. Patients of CRS typically present with various symptoms including nasal obstruction, post nasal drip, headache, rhinorrhea and olfactory disturbance with a considerable impact on the quality of life. ${ }^{1}$
Nasal obstruction is the most common and severe complaint among patients who have CRS. ${ }^{2}$ The prevalence of nasal obstruction among patients undergoing FESS for CRS is reported to be between $83.5 \%$ and $98 \%$. The most prevalent and studied pathologic entity associated with CRS is nasal polyposis Furthermore, patients who have CRS with nasal polyposis seems to have a statistically higher incidence of nasal obstruction when compared with patients without nasal polyposis. ${ }^{2}$

The prevalence of nasal polyposis is $5 \%$. The prevalence of nasal polyposis in CRS patients is $38 \%$ according to 
Damn et al3, 38.8\% according to Deal et al and $39.1 \%$ according to Chaudhary et al. ${ }^{4,5}$

Polyp formation in the nasal cavity is due to chronic allergic rhinitis, chronic sinusitis and less commonly, underlying disease such as cystic fibrosis. Patients usually present with nasal obstruction, persistent nasal discharge (rhinorrhea), sinus infection, and loss of the sense of smell (anosmia) of prolonged duration. Multiple studies have reported on the efficacy of surgical and medical management of patients with chronic sinusitis and nasal polyposis. ${ }^{6,7}$

Medical therapies include treatment for underlying chronic allergic rhinitis using antihistamines and topical nasal steroid sprays. Although, for severe nasal polyposis causing severe nasal obstruction, treatment with shortterm systemic steroids is found to be beneficial.

Surgical intervention may be required if severe symptoms of obstruction and infection prove medical treatment to be ineffective. In over 50,000 patients per year, medical management fails to yield successful results and thus endoscopic sinus surgery (FESS) is performed to assist in alleviating symptoms. ${ }^{8}$

Little is known about the outcomes of patients electing to continue medical management or the comparative effectiveness of continued medical therapy with FESS. Thus, this study was performed to assess the subjective and objective improvement of all the patients of CRS with polyposis after three weeks of medical management and according to their percentage of improvement further management plan is decided either to continue medical treatment or to be taken for FESS. The patients who were taken for either medical treatment only or taken for FESS with combined medical treatment were assessed again after six weeks.

\section{METHODS}

This study was conducted by the Department of ENT, Mallareddy Institute of Medical Sciences during the period of one year.The study was conducted on 126 adult patients in the age group of 18-55 who fulfilled the CRS criteria as per American Academy (AA) i.e. eight weeks or greater of persistent symptoms and signs with at least two major factors or one major factor along with two or more minor factors (Table 1) and/or diagnosis of Nasal polyps by nasal endoscopic examination.

Pregnant women, patients with known psychiatric illness, those with recent attack of upper respiratory tract infection in last one month, patients with fungal sinusitis or those with massive nasal polyposis i.e grade 3 were excluded from the study.
Table 1: American academy of otorhinolaryngology and head neck surgery criteria for chronic rhinosinusitis (AAOHNS).

\begin{tabular}{|ll|}
\hline Facial pain/pressure & Headache \\
\hline Facial congestion/fullness & Fever \\
\hline Nasal obstruction/blockage & Halitosis \\
\hline Nasal discharge/purulence & Fatigue \\
\hline Discolored postnasal discharge & Dental pain \\
\hline Hyposmia & Cough \\
\hline Purulencein the nasalcavity & $\begin{array}{l}\text { Ear } \\
\text { pain/pressure/fullness }\end{array}$ \\
\hline
\end{tabular}

All the patients were treated medically for 3 weeks with antibiotic amoxyclav, steroid oral and in nasal spray form, and decongestants. Patients with polyposis were given a short course of antihistamines and leukotrine modifiers.

All the patients were assessed after 3 weeks of treatment. Assessment was based on the visual analogue scale, Saccharine test and endoscopic examination. The VAS score is scales from 1-10 and is based on nasal blockage or congestion, nasal discharge, headache or facial pain, olfactory disturbance and post nasal drip. In the saccharine test, a small amount of saccharine powder is placed on the medial aspect of the inferior turbinate $1-2 \mathrm{~cm}$ behind the leading edge. The patient is instructed to avoid sniffing or blowing of the nose and is instructed to swallow frequently. The transport time is the time from the application of the saccharine powder to the time at which the patient detects a sweet taste. The saccharine time is normally 5 to 8 mins, 12 mins is slow and more than 25 mins indicates a mucociliary transport disorder.

For endoscopic examination, nose is prepared with $4 \%$ topical xylocaine drops before start of rigid nasal endoscopy (0 degree).

The assessment is done on the basis of Lund Kennedy scoring (Table 2).

Table 2: Lund Kennedy scoring.

\begin{tabular}{|ll|}
\hline Location & Score \\
\hline Presence of polyp on left side & $0,1,2,3$ \\
\hline Presence of polyp on right side & $0,1,2,3$ \\
\hline Edema left & $0,1,2$ \\
\hline Edema right & $0,1,2$ \\
\hline Discharge left & $0,1,2$ \\
\hline Discharge right & $0,1,2$ \\
\hline
\end{tabular}

If the improvement is not significant (i.e <60\%) then the patient was taken for the surgery (functional endoscopic sinus surgery) with combined medical therapy after taking a CT Scan of Paranasal Sinuses but those showing significant improvement were continued on the medical therapy for next 3 weeks. 
Once again assessment was done as per the above for both medical as well as surgical treatment.

Statistical analysis was performed by the SPSS program for Windows, version 17.0. Continuous variables are presented as mean $\pm \mathrm{SD}$, and categorical variables are presented as absolute numbers and percentage. The comparison of normally distributed continuous variables between the groups was performed using Student's t test. Within the groups, paired t test was used. Nominal categorical data between the groups were compared using Chi-squared test or Fisher's exact test as appropriate. For all statistical tests, a p value less than 0.05 was taken to indicate a significant difference.

\section{RESULTS}

Out of the 126 patients, $99(78.6 \%)$ patients showed improvement with medical treatment and 27 (21.4\%) of them had to undergo FESS. The predominant age group among the patients with chronic rhinosinusitis whether undergoing medical or surgical treatment was 41-50 years of age (Figure 1).

Majority of the patients were males who accounted to a total of $91(72.2 \%) .69(69.7 \%)$ were medically treated and $22(81.5 \%)$ were treated with FESS after the medical treatment. $30(30.3 \%)$ of the women were medically treated and out of the 27 patients surgically treated, only $5(18.5 \%)$ were females (Figure 2).

The VAS score at the base line was $4.49 \pm 0.84$ in the medical regime patients and $7.36 \pm$ in the MR+FESS patients. There was a considerable reduction in the score after 3 weeks and further after 6 weeks.

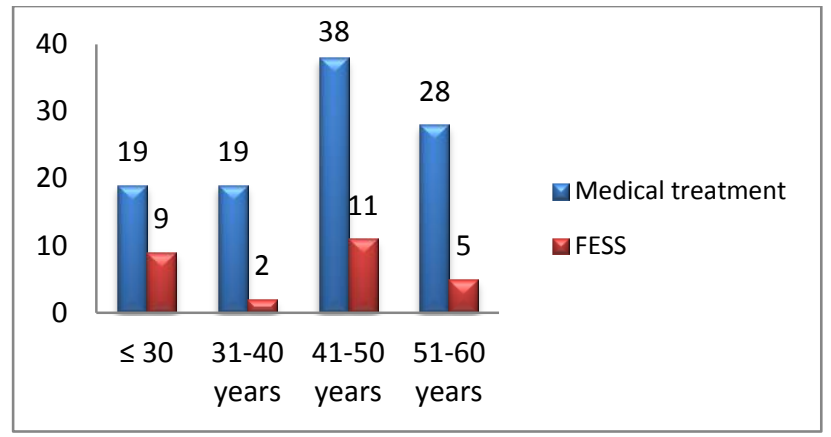

Figure 1: Age wise distribution of patients (in \%).

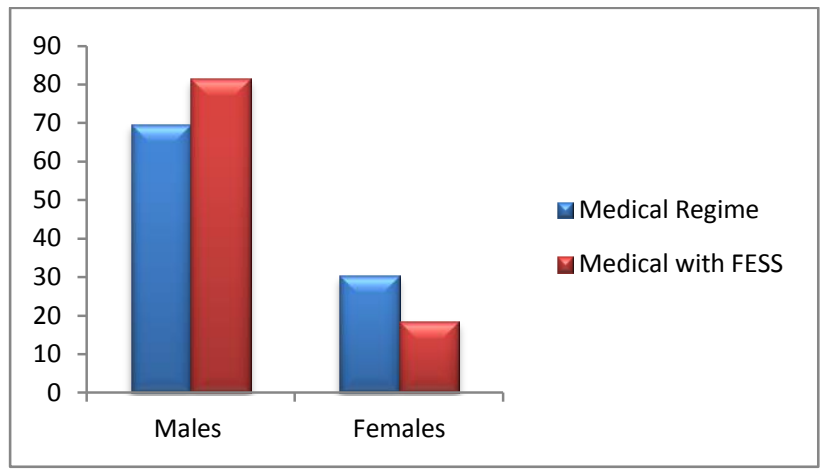

Figure 2: Gender wise distribution of patients (in \%).

Initial Nasal Endoscopic score patients on medical treatment was 7.97 , which reduced to 2.86 after three weeks and to 1.08 after six weeks. Among patients with surgical intervention, initial score was 11.0, 6.80 after three weeks and 1.40 after six weeks

Table 3: Various scores of treatment at baseline, after 3 weeks and after 6 weeks.

\begin{tabular}{|c|c|c|c|c|c|c|}
\hline & \multicolumn{2}{|l|}{ At baseline } & \multicolumn{2}{|c|}{ After 3 weeks } & \multicolumn{2}{|l|}{ After 6 weeks } \\
\hline & $\begin{array}{l}\text { Medical } \\
\text { regime }\end{array}$ & $\begin{array}{l}\text { Medical } \\
\text { regime + } \\
\text { FESS }\end{array}$ & $\begin{array}{l}\text { Medical } \\
\text { regime }\end{array}$ & $\begin{array}{l}\text { Medical } \\
\text { regime+ } \\
\text { FESS }\end{array}$ & Medical regime & $\begin{array}{l}\text { Medical regime + } \\
\text { FESS }\end{array}$ \\
\hline Mean VAS score & $4.49 \pm 0.84$ & $7.36 \pm 0.43$ & $1.69 \pm 0.43$ & $4.16 \pm 0.43$ & $0.67 \pm 0.19$ & $1.20 \pm 0.14$ \\
\hline $\begin{array}{l}\text { Mean endoscopic } \\
\text { score }\end{array}$ & $7.97 \pm 2.79$ & $11.00 \pm 1.41$ & $2.86 \pm 1.10$ & $6.80 \pm 0.84$ & $1.08 \pm 0.77$ & $1.40 \pm 0.55$ \\
\hline $\begin{array}{l}\text { Mean saccharine } \\
\text { score }\end{array}$ & $7.92 \pm 2.92$ & $15.20 \pm 5.89$ & $6.03 \pm 1.56$ & $10.40 \pm 5.03$ & $5.69 \pm 1.04$ & $6.80 \pm 3.42$ \\
\hline
\end{tabular}

Similar was the case with saccharine score which was 7.92 initially, 6.03 after three weeks, 5.69 after six weeks in Medical regime group. In patients on medical regime and FESS, initial mean score was 15.20, 10.40 after three weeks, 6.80 after six weeks (Table 3).

There was considerable improvement of the patients in three weeks and 6 weeks of treatment as seen by the three methods of assessment. VAS showed an improvement of $62.4 \%$ in the patients on medical regime alone and this was $43.4 \%$ in the patients with surgical intervention. $64.2 \%$ and $23.9 \%$ improvement was seen in medical regime patients in nasal endoscopy and saccharine test respectively and the same was $38.9 \%$ an $31.1 \%$ in the FESS patients (Table 4). 
Table 4: Percentage of improvements after 3 weeks and 6 weeks in both groups.

\begin{tabular}{|lllll|}
\hline & After 3 weeks & & After 6 weeks & \\
\hline & Medical regime & Medical Regime + FESS & Medical regime & Medical Regime + FESS \\
\hline Mean VAS improvement & $62.36 \%$ & $43.48 \%$ & $85.08 \%$ & $83.70 \%$ \\
\hline $\begin{array}{l}\text { Mean endoscopic } \\
\text { improvement }\end{array}$ & $63.43 \%$ & $40.31 \%$ & $65.01 \%$ & $95.04 \%$ \\
\hline $\begin{array}{l}\text { Mean saccharine } \\
\text { Improvement }\end{array}$ & $23.86 \%$ & $31.58 \%$ & $28.16 \%$ & $55.26 \%$ \\
\hline
\end{tabular}

\section{DISCUSSION}

Chronic rhinosinusitis (CRS) remains an extremely common clinical condition with an estimated lifetime prevalence of $12 \%$. The most prevalent and studied pathologic entity associated with CRS is nasal polyposis. Nasal polyps usually manifest after the age of 20 years with affected men out numbering women $2: 1 .^{5}$

Maximum numbers of patients were in the age group of $41-50$, representing $38 \%$ of the total patients. Males were the predominant gender, accounting for $71 \%$ of the total study group. Thus male to female ratio was 2.4:1. Many studies also have found male preponderance. ${ }^{9-12}$

Out of all the three parameters studied (visual analogue score (VAS), nasal endoscopy score and saccharine score), saccharine test was found to be normal in $88 \%$ patients and only $12 \%$ patients showed prolonged saccharine time (>12 mins). Therefore, we found the saccharine test not to be an effective method to identify the patients needing surgical intervention.

In the present study, $78.6 \%$ of the patients showed a great improvement after the medical treatment and did not require surgical intervention. Similar results were found by. Ragab $\mathrm{S}$ et al have also shown in their study that such patients should be initially targeted with maximal medical therapy with surgical treatment being reserved for cases refractory to medical treatment. ${ }^{13}$

In yet another study by Dufouret al it was concluded that cases refractory to intensive medical management showed improvement in quality of life after surgical management. ${ }^{14}$ Similar was the case in $27(21.4 \%)$ in our study. Many other researches have shown that medical and surgical treatments are equally effective in patient of CRS with polyposis. ${ }^{15-18}$ In another study done by Ebba Heden Blomquist et al showed that medical treatment seems to be sufficient to treat most symptoms of nasal polyposis. $^{19}$

We saw that after 3 weeks patients on only medical treatment showed only $26.47 \%$ improvement in polyp size on nasal endoscopy but in subjective assessment (VAS), they showed $62.36 \%$ improvement. Though there was not significant improvement in polyp size, these patients were continued only on medical treatment.

Individual aspects of CRS medical therapy, particularly nasal corticosteroids, have been published extensively. ${ }^{6-8}$ Similarly, ESS has been shown to reduce nasal and sinus symptoms up to one year postoperatively. Conversely, as Khalil et al demonstrated in a large review of randomized controlled studies coparing the two arms of surgical and medical therapy, ESS does not clearly confer additional clinical benefit to medical treatment. ${ }^{17}$ Gliklich et al described significant improvement in both medically treated and surgically treated patients. ${ }^{18}$ According to a randomized controlled study done by Ebba Heden Blomqvistet al medical treatment is sufficient to treat most symptoms of nasal polyposis except in case where nasal obstruction is the main problem after steroid treatment where surgical treatment is indicated. ${ }^{19}$

The same was emphasized by Sameh M Ragab et al, who said CRS should be initially targeted with maximal medical therapy with surgical being reserved for cases refractory to medical therapy. ${ }^{13}$ The presence nasal polyps was not a poor prognostic factor for the efficacy CRS therapy either surgical or medical therapy. In one of the prospective, multi institutional studies done by Timothy L. Smith et al, demonstrated the improvement in quality of life (QOL) in both medically treated and surgically treated patients, with CRS though patients treated surgically experienced significantly more improvement in disease specific QOL. ${ }^{20}$

Thus, we found most of our outcomes were in good conjunction with earlier studies over medical versus surgical treatment of CRS with polyposis.

\section{CONCLUSION}

Medical treatment was found to be sufficient to treat most symptoms of CRS with nasal polyposis. 99 patients showed average improvement of $62 \%$ and 27 patients showed average improvement of $43 \%$ after three weeks of medical treatment.

Patients who underwent only medical treatment and those who were treated with combined medical and surgical treatment showed equal amount of improvements after 
six weeks. Therefore, surgery does not confer any additional benefit over medical treatment, except in patients who need the surgery. Selection of those patients who will benefit from surgery should be based on the patient's symptoms and not on the examiner's polyp score. Quality of life is not proportional to polyp size (upto grade 2). Though the polyp size improvement is significantly different in both the groups (group A-65\%, group $\mathrm{B}-95 \%, \mathrm{P}=0.019$ ), yet the overall improvement in the patients of both the group remained almost equal (group A-85\%, group B-84\%, $\mathrm{P}=0.806$ ).

Both nasal endoscopy and VAS score were efficient to diagnose patients who required surgical intervention, but that was not the case with saccharine test.

Funding: No funding sources

Conflict of interest: None declared

Ethical approval: The study was approved by the Institutional Ethics Committee

\section{REFERENCES}

1. Gliklich RE, Metson R. The health impact of chronic sinusitis in patients seeking otolaryngologic care. Otolaryngol Head Neck Surg. 1995;113:104-9.

2. Bhattacharya N. Symptom outcomes after endoscopic sinus surgery for chronic rhinosinusitis. Arch Otolaryngol Head Neck Surg. 2004;130(3):3299-33.

3. Damm M, Quante G, Jungehuelsing M, Stennert E. Impact of functional endoscopic sinus surgery on symptoms and quality of life in chronic rhinosinusitis. Laryngoscope. 2002;112:310-5.

4. Deal RT, Kountakis SE. Significance of nasal polyps in chronic rhinosinusitis symptoms and surgical outcomes. Laryngoscope. 2004;114:1932-5.

5. Chaudhary N, Kapoor R, Motwani G, Gandotra SC. Functional endoscopic sinus surgery results in 69 patients. Indian J Otolaryngol Head Neck Surg. 1999-2000;52(1):5-8.

6. Keith P, Nieminen J, Hollingworth K, Dolovich J. Efficacy and tolerability of fluticasone propionate nasal drops 400 microgram once daily compared with placebo for the treatment of bilateral polyposis in adults. Clin Exp Allergy. 2000;30:1460-8.

7. Penttila M, Poulsen P, Hollingworth K, Holmstorm M. Dose related efficacy and tolerability of fluticasone propionate nasal drops 400 microgram once daily and twice daily in the randomized study in adult patients. Clin Exp Allergy. 2000;30:94-102.

8. Lund VJ, Flood J, Sykes AP, Richards DH. Effect of fluticasone in severe polyposis. Arch otolaryngol head and neck surg. 1998;124:515-8.

9. Kaliner MA, Osguthorpe JD, Fireman P, Anon J, Georgitis J, David ML. Sinusitis: bench to bedside. Current findings, future directions. J Allergy Clin Immunol. 1997;99(6 pt 3):S829-48.

10. Osguthorpe JD, Hadley JA. Rhinosinusitis: current concepts in diagnosis and management. Med Clin North Am. 1999;83:27-42.

11. Benson V, Marano M. Current estimates from the National Health Interview Survey, 1993. Vital Health Stat. 1994;10:1-121.

12. Tos M, Mogensen C. Mucous production in chronic maxillary sinusitis. A quantitative histopathalogical study. Actaotolaryngol (Stockholm). 1984;97:151-9.

13. Ragab SM, Lund VJ, Scadding G. Evaluation of the medical and surgical treatment of chronic rhinosinusitis: a perspective, randomized, controlled trial. The Laryngoscope. 2004;114(5):923-30.

14. Dufour X, Bedier A, Ferrie JC, Gohler C, Klossek JM. Laryngoscope. 2004;114:1982-7.

15. $\mathrm{T}$ Lildholt. J. Fogstrup, $\mathrm{N}$ Gammelgaard, B Kortholm and C Ulose. ActaOtolaryngol (Stockh) 1988; 105: 140-143.

16. Alobid I, Benítez P, Bernal-Sprekelsen M, Roca J, Alonso J, Picado C. J Allergy. 2005;60(40):452-8.

17. Khalil HS, Nunez DA. Functional endoscopic sinus surgery for chronic rhinosinusitis. Cochrane Database Syst Rev. 2006;3:CD004458.

18. Gliklich RE, Metson R. Effect of sinus surgery on quality of life. Otolaryngol Head Neck Surg. 1997;117:12-7.

19. Blomqvist EH, Lundblad L, Anggård A, Haraldsson PO, Stjärne P. A randomized controlled study evaluating medical treatment of nasal polyposis. J Allerg Clin Immunol. 2001;107(2):224-8.

20. Smith TL, Kern RC, Palmer JN, Schlosser RJ, Chandra RK, Chiu AG, et al. Medical therapy vs surgery for chronic rhino sinusitis: a prospective multi-institutional study. Intern Forum of Allerg Rhinol. 2011;1(4):235-41.

Cite this article as: Modgil N. Evaluation of the medical and surgical management of chronic rhinosinusitis with polyposis. Int J Otorhinolaryngol Head Neck Surg 2016;2:120-4. 